\title{
JOHN STURGEON MACKAY, M.A., LL.D.
}

Dr John S. Mackay, the first President of our Society, died on the 25th of March, 1914, at his residence, 69 Northumberland Street, Edinburgh. In view of the unrivalled services he rendered the Society, and the active interest he took in its work from its inception, it has been judged fitting that the Proceedings should contain a short record of his life.

John Sturgeon Mackay was of Highland descent by his father's side, but of Lowland descent by his mother's, and it was during a visit of his mother to her relatives at Aucheucairn, near Kirkcudbright, that he was born on the 22nd of October 1843. It was in Perth, however, he spent his boyhood and attended school. Fortunate in growing up in a city situated amid delightful scenery and associated with many stirring events of Scottish history, he was not less happy in the school where he was educated. Dr Miller, the rector of Perth Academy from 1837 to 1881 , was a remarkable man; in the words of one of his distinguished pupils, "under his reign the Academy was less a school than a notable provincial college." The obituary notice of Dr Miller, contributed by Dr Mackay to the Proceedings of the Royal Society of Edinburgh, Vol. XIX., Session 1S91-92, presents a atriking picture of the finest type of the old Scottish schoolmaster, and outlines in terse but graphic language the relations between the master and the pupil. From that notice I extract the following statement of the course of mathematics through which Dr Miller conducted his junior and senior classes:- "The course consisted of the theory of arithmetic, algebra, plane and solid geometry, 
geometrical conics, plane and spherical trigonometry, dynamics, elementary physics and astronomy, and inorganic chemistry. Occasionally he had pupils who gave a third or even a fourth year's attendance, for which he would accept no fee, and be took particular pleasure in initiating them into the mysteries of the calculus." One might be tempted to hint that such a wide range of subjects would be only superficially covered, but I know, from frequent conversations with Dr Mackay, that in bis case at least the work was very thoroughly done; to the end of his days he could repeat verbatim many of the enunciations in geometry and in spherical trigonometry as he had learned them under Dr Miller.

The rector was a really competent mathematician; but " his culture was not that of science alone, for he was widely read in literature, and he could grapple with the philosophical and theological questions of the day." An Academy boy had excellent opportunities for a sound training in English, Latin, and Greek, as well as in Mathematics and Science, and when Mackay matriculated at St Audrews in 1859, he was admirably prepared for entering on University studies.

During the years in which he was a student at St Andrews the classes were small, and the students were bound together in a cameraderie that is impossible in a large University. At that period the curriculum for the M.A. degree was fixed, and it was usual for the students who entered the University in the same year to keep together and attend the same lectures throughout the course. Dr Mackay was fond of recalling incidents of his undergraduate days, and he could trace the subsequent career of nearly every member of his own class. He had as fellow-students several men who afterwards rose to eminence; of them all, the one for whom he had the greatest admiration was the late Rev. Dr Crichton of Annan. He considered Dr Crichton to be one of the finest scholars St Andrews ever sent forth.

Mackay was soon recognised as one of the "good students." He took kindly to every subject included in the degree course, and was in the honours list of every class. He read widely in 
general literature, and he did not confine his technical studies to prescribed books and authors. The stores of learning he then amassed were a permanent possession, and there are few graduates who retain through life as ready a command as he did of the learning acquired at the University.

He completed his attendance at the classes, and passed all the examinations for the M.A. Degree in 1863. He did not graduate, however, till 1865, as he wished to take the examinations for an Honours Degree, but he was prevented by various causes from realising his wish. He had thoughts of going forward to the ministry of the United Presbyterian Church, and as at that time the theological classes met for two months only in the autumn of each year, he followed a usual custom of taking a teaching engagement, and he found congenial occupation as assistant to Dr Miller in Perth Academy. He attended the Theological Hall for three sessions, but he gradually made up his mind to devote himself to teaching as a profession, and after an apprenticeship of three years under Dr Miller, he obtained an appointment on the staff of the Edinburgh Academy. From 1866 till his retiral in 1904, he remained at the Academy, for the greater part of that period as head mathematical master.

During his early years in Edinburgh he spent a considerable part of his leisure in the study of botany and geology, and he attended several University classes, taking part in the various class excursions. He retained his interest in these subjects to the last, and he often expressed to me his belief in the value of botany as a subject of general education. His knowledge of botany was, for an amateur's, remarkably accurate, and, like all his knowledge, was always at hand.

In the early seventies he had a long holiday in France, and from that date to the close of his life, there were few years in which he did not spend the greater part of his vacation on the Continent, and chiefly in Paris. He gradually acquired a thorough mastery of French, both literary and colloquial, and read very widely in French literature; he made many friends in Paris, and indeed seemed to feel quite as much at home 
there as in Edinburgh. Though he did not obtain the same proficiency in German and Italian as in French, he had a really good knowledge of these languages, and when one was asked to recommend him a book, it made very little difference to him whether the language in which it was composed was English, French, German or Italian. He had, besides, a scholarly knowledge of Latin and Greek, so that when he had fairly entered on historical studies he had at command a linguistic equipment such as professed historians do not always possess.

In Dr Mackay's notice of bis old master occurs a sentence that might have been written of himself:- "While he was interested in science mainly for its own sake and for the sake of the benefits which its discoveries conferred on mankind, he was keenly alive to the educational importance of its historical development, and familiarised his pupils with the names and the achievements of the great masters from Euclid downwards." It is not unreasonable to conclude that Dr Mackay's interest in the history of mathematics was awakened in his school days; that interest was certainly of life-long duration. From an early period his attention was directed to the Greek geometers, and one of the disappointments of his life is associated with these earlier studies. The incident is so graphically described in a notice of Dr Mackay that appears in the May number of The Edinburgh Academy Chronicle over the initials D. W. T., that I cannot refrain from quoting the whole passage :-

"Of all the great Alexandrine geometers, the works of one only, Pappus, remained to be edited. The Oxford scholars of the eighteenth century had neglected him, and a sixteenthcentury Latin translation, together with a bare reprint of a small part of his text by a French editor, was all that was extant. For years Mackay had given his holidays to the collation of manuscripts, and his nights to the patient interpretation of the old mathematician; and at last his work was done, and the whole book lay complete in his desk, in his beautiful handwriting, with a wealth of drawings. He went in one day to Williams and Norgate's foreign bookshop in 
Frederick Street, then managed by $\mathrm{Mr}$ Wheatley, an excellent scholar; and $\mathrm{Mr}$ Wheatley said, 'I've sumething to-day, $\mathrm{Mr}$ Mackay, that will interest you,' and he produced the first volume of Hultsch's edition of Pappus, a work that has held the field to this day, and is the magnum opus of its distinguished author. Mackay took the book home. He found that Hultsch and he had collated the same MSS., had arrived at the same interpretations, had noted the same difficulties, down to the smallest-a wrong letter, an omitted кát-the German had noted them all. Some men, in Mackay's place, would have made all haste to send their own book to the printer, hoping to gain, by all but contemporaneous publication, some part of the scholar's reward. But Mackay had a sterner code of duty and of honour. The work was done, and well done; the needs of his few fellow-students of Greek mathematics were sufficiently met; and what was lost was a matter for him alone. A few years later, in a less direct and poignant way, Mackay found himself forestalled by the publication of Allman's Greek Geometry. 'I'his was a book that Mackay could have written to perfection, and perbaps with even greater learning than the Irish scholar displayed."

The head mathematical master of the Academy had gradually become known in educational circles as a scholar and as a mathematician, and when, at a meeting held in the Mathematical Class Room of Edinburgh University on the 2nd of February 1883, it was agreed to institute a Society to be called "The Edinburgh Mathematical Society," bis unique position was recognised in his appointment as its first President. From that day till the close of his life he was unwearied in his efforts to promote the welfare of the Society. Until failing health confined him to the house in the evening, he was regular in his attendance, and by his kindness and courtesy in welcoming new members, he greatly contributed to that friendly atmosphere which distinguished the meetings. The Society had a hard struggle in its early days. It first Secretary, Dr Knott, was appointed Professor of Physics at Tokio soon after the Society was founded. In the second session the late 
Mr A. Y. Fraser was elected as Dr Knott's successor in the Secretaryship, and he held the office till the end of the sixth session. During these critical years Dr Mackay and Mr Fraser were in constant communication about the affairs of the Society, and it is in no small degree due to their devoted service that the early difficulties were overcome and the new organisation fairly launched on its career.

A glance at the index of the first twenty volumes of the Proceedings, drawn up with consummate skill by Dr Mackay himself, shows how regular were his contributions. Most of his articles are geometrical, and they always include historical notes and references. They represent in every instance the results of his own investigation, and I think I am correct in stating that in no single case has his accuracy been impugned. The first paper he submitted is an admirable example of his characteristic style-precision of language, lucidity of arrangement, and accuracy of citation. In the course of a long series of articles he throws a flood of light on the origin of many geometrical theorems, traces their developments, indicates their relationships, and often gives to them their finishing touch. He settled the source of the misnamed Simson Line, and in one of his last papers he made important additions to the bibliography of the envelope of that line. The number of references in his articles, the obscure journals and books that furnished valuable results, the variety of languages from which the facts are cited, the scrupulous accuracy of quotation and reference, can best be understood by those who have themselves attempted historical research. There is no parade of learning, but the fruit of long and laborious first-hand investigation is evident on every page.

There is one field of investigation which Dr Mackay bad made peculiarly his own; it is what he himself called English "mathematical journalism" as distinct from the Proceedings and Transactions of learned Societies. No one who desires to become acquainted with what may be called the more homely forms of English mathematical research can find a better-or rather, any other-guide than his article Notice sur le 
Journalisme Mathématique en Angleterre, contributed to the French Association for the Advancement of Science (Congrès de Besançon, 1893). The preparation of that article was in itself a remarkable feat. One of the members who had promised a paper was unable to be present, and on the afternoon of the day before the paper was set down for reading Dr Mackay was asked to take the absent member's place. With his usual courtesy, he agreed to try "to put some things together"; the result was the notice in almost the exact form in which it appears in the volume of the Association for that year.

Although Dr Mackay's contributions to the Proceedings of our Society are mainly geometrical, it is proper to note that the Report on the Teaching of Arithmetic in Vol. VI. owes very much to him, and many of the articles are from his pen.

In recognition of the great services he bad rendered the Society, he was elected an Honorary Member in November 1894.

Of the textbooks written by Dr Mackay, the most characteristic was his Elements of Euclid, Books I to VI, published in 1884 , and enlarged in 1888 by the addition of the usual propositions from Books XI and XII. Many of its distinctive features, especially its historical references, were soon imitated by other writers; but there are many subtle deviations from Simson's text that escape the notice of the casual reader, and that lend a unity to several propositions that is usually ignored. The composition of this book was a labour of love; much of the original manuscript had to be sacrificed to the exigencies of publication; but as a textbook of general education it is, in my opinion, the best adaptation of Euclid's Elements that we possess. When in the early years of the present century the demand for a new type of textbook arose, he felt constrained to comply with it, and he produced his Plane Geometry (Books I, II, III, in 1904; Books IV, V, in 1905). The new book is an excellent piece of work, but he did not fully sympathise with the new movement, and his attitude is, I think, reflected in this later book. 
In 1869 he published a volume of Arithmetical Exercises, and in 1899 a formal textbook with the title Arithmetic, Theoretical and Practical. (The historical bent of the writer shows itself at every convenient opportunity, and a careful reader may learn some curious facts).

Of Dr Mackay's other activities I shall only make brief mention. He was a member of the A.I.G.T. from its origin, and took an active interest in its work. A Fellow of the Royal Society of Edinburgh, he servea for two periods on the Council, and his services were specially valuable on the Library Committee. He frequently attended the meetings of the French Association for the Advancement of Science, and corresponded regularly with several well-known French mathematicians. He was a member of the Permanent International Commission for Mathematical Bibliography, and he was of special service through his great linguistic attainments. He took a warm interest in the Franco-Scottish Society, and was a member both of the Council and of the Executive.

In 1887 his old University recognised his great learning by conferring on him the Honorary Degree of LL.D.

In 1904 he retired from his position in the Academy. The number of the Academy Chronicle from which I have already quoted contains a graceful tribute to his memory from two of his pupils, and those who wish to understand the relations that existed between Dr Mackay and generations of boys should read these characteristic appreciations of their old master. Like many bachelors, he was fond of young people, and speedily gained their confidence; no master was ever prouder of the successes of his pupils or took a livelier interest in their after welfare; the visits he received from those who had gone out into the world and risen to eminence were honourable to master and pupil alike.

In his youth Dr Mackay was an enthusiastic golfer. During one of his sessions at St Andrews he and a fellow-student determined to make one round of the links, if it were possible, every day; they succeeded on all but three days, when the weather proved too much even for their exuberant spirits, and 
compelled them to desist before they had well begun. In later years he became a member of a bowling-green, and acquired considerable skill at the game, but the sport in which he specially excelled was skating. He hoped that after his retiral he would be able to resume his golf, but he had, through want of practice, lost much of his youthful skill, and he seldom appeared on the links. His daily walk provided him with such physical exercise as he found it necessary to take.

He was a delightful companion, blessed with the saving grace of humour, and those who had the privilege of his friendship will never forget the genial talk in which he ranged over the most varied fields of knowledge, passing lightly from the gossip of the day to the discussion of the deepest problems of philosophy. His culture was both literary and scientific, his scholarship was exact, but free from pedantry, and his vast stores of knowledge were always at band, ready for instant use. Of a genial and kindly disposition, he was ever ready to offer a helping hand to his less fortunate fellowmen. Charitable in his judgments of others, he kept a high standard of ethics for himself, and was his own severest critic.

In the beginning of this year the approach of serious trouble was indicated by the rapid failure of his eyesight; he became very ill in the first days of March, and after a short rally passed away on the afternoon of the 25 th of that month. On Saturday, the 28th, he was laid to rest in the city where he spent his boybood, and where he laid the foundations of that learning for which in after life he was so distinguished.

George A. Gibson. 